\title{
Familial non-medullary thyroid cancer: a critical review
}

\author{
M. Capezzone ${ }^{1} \cdot$ E. Robenshtok ${ }^{2,3} \cdot$ S. Cantara ${ }^{1} \cdot$ M. G. Castagna ${ }^{1}$ (i)
}

Received: 7 July 2020 / Accepted: 25 September 2020 / Published online: 6 October 2020

(c) The Author(s) 2020

\begin{abstract}
Background Familial non-medullary thyroid carcinoma (FNMTC), mainly of papillary histotype (FPTC), is defined by the presence of the disease in two or more first-degree relatives in the absence of other known familial syndromes. With the increasing incidence of PTC in the recent years, the familial form of the disease has also become more common than previously reported and constitutes nearly $10 \%$ of all thyroid cancers. Many aspects of FNMTC are debated, concerning both clinical and genetic aspects. Several studies reported that, in comparison with sporadic PTCs, FPTCs are more aggressive at disease presentation, while other authors reported no differences in the clinical behavior of sporadic and familial PTCs. For this reason, recent guidelines do not recommend screening of family members of patients with diagnosis of differentiated thyroid cancer (DTC). FNMTC is described as a polygenic disorder associated with multiple low- to moderate-penetrance susceptibility genes and incomplete penetrance. At the moment, the genetic factors contributing to the development of FNMTC remain poorly understood, though many putative genes have been proposed in the recent years.

Purpose Based on current literature and our experience with FNMTC, in this review, we critically discussed the most relevant controversies, including its definition, the genetic background and some clinical aspects as screening and treatment.
\end{abstract}

Keywords Familial papillary thyroid cancer $\cdot$ Familial non medullary thyroid cancer $\cdot$ Syndromic thyroid cancer

\section{Definition of familial cancer}

A comprehensive and accurate family cancer history is essential for cancer risk assessment, reflecting complex interactions among inherited genetic susceptibilities, shared environmental and behavioral factors [1]. An estimated 20\% of cancer patients have a positive family history of cancer without the specified criteria for hereditary cancer, and are generally at a moderately increased risk of developing cancer when compared with the general population. These Familial cancers $(F C)$, defined by the diagnosis of the same type of cancer in two or more first-degree relatives in the

M. G. Castagna

mariagrazia.castagna@unisi.it

1 Section of Endocrinology and Metabolism, Department of Medical, Surgical and Neurological Sciences, University of Siena, Policlinico Santa Maria alle Scotte, Viale Bracci 1, 53100 Siena, Italy

2 Institute of Endocrinology, Rabin Medical Center-Beilinson Hospital, Petach Tikva, Israel

3 Sackler Faculty of Medicine, Tel Aviv University, Tel Aviv, Israel absence of known germline mutations, have been described for most major organ systems. A list of the definitions of most frequent familial cancers is shown in Table 1 [2-7].

\section{Epidemiology of familial cancer}

Epidemiologists used family history (FH), usually of firstdegree relatives (FDRs), as a marker for genetic risk, knowing that $\mathrm{FH}$ reflects the consequences of genetic susceptibilities, shared environment, and common behaviors.

Individuals with a positive family history for certain types of cancers can have an increased risk of developing cancer themselves. Several studies indicated that individuals with a family history of cancer are two- to threefold more susceptible to develop the same cancer than those without such a history [8]. To evaluate the rate of familial cancers, population-based studies were used but are limited if a disease or its hereditary form is rare. Case-control study design has also been employed, but again, if most cases of disease are sporadic, there may be insufficient power to detect aggregation within families. As a remedy, other studies recruited subjects on the basis of their family history of disease [9]. 
Table 1 Definition of human familial cancers other than carcinoma of the thyroid

\begin{tabular}{lll}
\hline Organ & Definition of familial cancer & Ref. \\
\hline Pancreas & Two or more relatives affected with pancreatic cancer & [2] \\
Lung & One first or second degree relative with lung cancer & [3] \\
Gastric & Two first- or second-degree relatives before the age of 50 years or three first- or second-degree relatives independent of \\
& age & [4] \\
Breast-ovarian & $\begin{array}{l}\text { (a) Two cases in family members below 50 years or ovarian, peritoneal or tubal cancer in family members at any age; } \\
\text { (b) Three cases of breast cancer or ovarian, peritoneal or tubal cancer in family members at any age; }\end{array}$ \\
& (c) One case of breast cancer in a family member below the age of 50 years or bilateral breast cancer in a family member \\
Melanoma & at any age & Two first-degree relatives or three or more on the same side of the family (irrespective of degree of relationship) \\
Prostate & Two first-degree relatives at any age, or one first-degree relative and two or more second-degree relatives diagnosed at \\
& any age & [6] \\
\hline
\end{tabular}

Nevertheless, the magnitude of the association with family history varies between studies, cancer sites, and strata of sex and age, being generally stronger for younger probands. The prevalence of a family history of breast cancer has been estimated to range from 5 to $22 \%$, of colon cancer from 2.0 to $9.4 \%$, of ovarian cancer from 1.1 to $3.5 \%$, of endometrial cancer from 0.5 to $1.4 \%$, and of prostate cancer from 4.6 to $9.5 \%$ [10].

For these reason, it is important to consider that when family history is used to assess the risk of cancer, its accuracy and completeness must be taken into account. In fact, it may happen that the family history is reported incorrectly or that the person is not properly aware of family members with cancer. Furthermore, sometimes small families or premature deaths may limit the information obtainable from the family history itself.

\section{Familial non-medullary thyroid carcinoma (FNMTC)}

\section{Controversy in the definition of FNMTC}

In 1955, Robinson and Orr published the first report of isolated familial papillary thyroid cancer affecting 24-year-old identical twins [11]. Since that time, many reports have been published about the presence of kindreds with differentiated thyroid cancer (DTC) suggesting the real existence of a familiar form of non-medullary thyroid cancer (FNMTC). The accepted definition of FNMTC is the occurrence of the disease in two or more first-degree relatives of the patient [12]. The traditional definition of FNMTC was based primarily on large population-based analysis, where a national cancer registry was present that documented how the relatives of non-medullary thyroid cancer patients had a higher risk of developing the same type of cancer, often the highest among all cancer types $[13,14]$. However, this definition has been discussed since the presence of only two affected members in kindreds may represent a fortuitous association of the disease, as suggested by Charkes [15], who applied an exact probability measure to a series of first-degree family members with FNMTC. According to his mathematical simulation, 62-69\% of 2-hit families are sporadic occurrences and thus, only families with 3 or more affected firstdegree relatives should be considered for clinical and genetic investigations of FNMTC. However, recently a paper from the Swedish Family Cancer database that included 14.7 million individuals, was used to estimate familial cancer risk for the 25 most common cancer sites and has been highlighted as the first-degree relatives of patients affected by small intestines, thyroid and testicular cancers are those most at risk of developing the same cancer [8]. If a parent was affected, risk for offspring was threefold for thyroid cancer. The same authors observed that more than $90 \%$ of familial cancers were in families with two affected members, with the exception of prostate cancer (87\%). Families with 3 or more concordant cases accounted for more than $1 \%$ of all cancer only for prostate and breast cancer. The authors hypothesized that the low proportion of families with 3 or more affect individuals is likely to define the genetic architecture of familial cancer; high-penetrance predisposition is rare compared to low-penetrance risk predisposition signaled by two-case families. Since ionizing radiation is the only established environmental risk factor for thyroid cancer, the majority of familial cases where two family members were affected, are probably caused by low-penetrance genes [8]. More recent data suggest that FNMTC is a polygenic disorder with variable penetrance likely associated with a low-to-moderate number of low-penetrant alleles [16]. Genome-wide association studies have pinpointed at least ten loci having odds ratios of $\sim 1.2$ to $\sim 1.8$, indicating that low-penetrance predisposition variants play important roles. Therefore, the presence of only two affects does not exclude familial tumor. Such features, as the presence of genetic anticipation, should also be considered in the definition of FNMTC. The age of onset of the tumor, even more than 
the number of affected family members, is an important parameter for the existence and likelihood of a family-type tumor. In fact, familial risks tend to decrease with the age of diagnosis of the probands for some cancer sites [17]. The presence of genetic anticipation has been demonstrated in FNMTC patients suggesting the inheritance of this familial form of thyroid cancer even in cases where only two members of a family are affected [18]. A potential bias when diagnosing FNMTC could be related with the presence of familial multinodular goiter (MNG). In areas with iodine deficiency MNG is common and, although the population incidence of MNG far exceeds that of thyroid cancer, there is also evidence that genetic susceptibility to MNG and to NMTC may be related [19]. In fact, families segregating an autosomal dominant trait for MNG often include cases of NMTC. Several studies have reported genetically linked loci for familial MNG and actually, FNMTC and its relationship with familial MNG are now recognized clinical entities with well identified MNG loci [20].

\section{Does a driving gene for familial non-medullary thyroid cancer exist?}

The presence of a genetic basis for FNMTC is controversial. For familial forms, at least three distinct clinical presentations have been reported: (1) a particularly rare syndromic familial form, in which thyroid carcinoma is associated with non-thyroid diseases such as Gardner syndrome, Cowden syndrome, Werner's syndrome or Carney complex in which a responsible gene has been identified; (2) a second phenotype, also very rare, in which familial thyroid cancer is associated with a particular histotype with well-defined susceptibility loci; and (3) the most frequent form, where familial papillary thyroid cancer (FPTC) is the only clinical manifestation in the absence of candidate genes. The syndromic group is characterized by a preponderance of nonthyroidal tumors and is associated with Mendelian cancer syndromes. The associated syndromes include Cowden syndrome, familial adenomatous polyposis (FAP) with its form Gardner syndrome, Carney complex, Werner and DICER1 syndromes [21-26] [Table 2].

To give reason for all non-syndromic FNMTC cases, some genomic regions considered as FNMTC predisposing loci have been reported in various studies. The first "locus" (called "thyroid carcinoma with oxyphilia", TCO) was located at position 19p13.2 in a single French family with a rare form of familial oxyphilic cell thyroid tumor (OMIM\# 603386) [27]. The TCO linkage was subsequently confirmed in other pedigrees although the phenotype of cell oxyphilia was associated only in few cases [28]. Another locus has been identified at position 1q21 in an American family affected by both FNMTC and papillary neoplasia of the kidney ("papillary thyroid carcinoma and papillary renal neoplasia", fPTC/PRN) [29]. A further susceptibility locus ("non-medullary thyroid carcinoma 1", NMTC1) was identified on chromosome 2q21 in a large family from Tasmania suffering from a high frequency of papillary carcinoma follicular variant [30]. Association between TCO and NMTC loci has also been reported [31] with the consequence of an increased risk in individuals that inherit both susceptibility genes. Loci associated with FNMTC are reported in Table 3.

For isolated FNMTC, no susceptibility locus was found and no germline mutations were demonstrated. The classic genetic alterations most commonly described in somatic PTC (point mutations of BRAF and RAS and rearrangements of RET/PTC, PPARy and TRK) have not been demonstrated at germline level in FNMTC. The hypothesis that FNMTC is a hereditable cancer, has been suggested by epidemiological studies and by the analysis of some national cancer registries which have shown that, among all types of cancer, nonmedullary thyroid carcinoma shows a significantly higher risk of developing in the first-degree relatives of an affected member compared to the general population $[13,14]$. The observation that the first degree relatives of an affected individual have an eight- to tenfold increased risk of developing the disease suggest that there must be an underlying germline

Table 3 Susceptibility loci associated with familial non-medullary thyroid cancer (FNMTC)

\begin{tabular}{llcl}
\hline Tumor & Chromosomal loci & Numero OMIM & Ref. \\
\hline TCO & $19 \mathrm{q} 13.2$ & 606240 & {$[27]$} \\
PTC/PRN & $1 \mathrm{q} 21$ & 606240 & {$[29]$} \\
NMTC1 & $2 \mathrm{q} 21$ & 6063831 & {$[30]$} \\
\hline
\end{tabular}

PTC Papillary thyroid cancer, PRN papillary renal neoplasm, TCO Thyroid tumors with cell oxyphilia

Table 2 Syndromes associated with familial non-medullary thyroid cancer (FNMTC)

\begin{tabular}{llll}
\hline Syndrome & GENE & Types of thyroid cancer (incidence \%) & Ref. \\
\hline Familial adenomatous polyposis & APC & Cribriform papillary thyroid cancer $(2-12 \%)$ & [22] \\
Cowden syndrome & PTEN & Classical or follicular papillary thyroid cancer $(>10 \%)$ \\
Carney complex type 1 & PRKARI & Follicular or Papillary thyroid cancer $(4-60 \%)$ & {$[23]$} \\
Werner syndrome & WRN & Follicular, Papillary or Anaplastic thyroid cancer $(18 \%)$ \\
DICER 1 syndrome & DICER1 & Multinodular thyroid hyperplasia and carcinoma () & {$[24]$} \\
\hline
\end{tabular}


mutation(s) that have not been discovered, yet. The presence of family forms for NMTC is described as a polygenic disorder associated with multiple genes with low to moderate or incomplete penetrance and variable expression as observed on reports of families with three or more affected members, horizontal transmission in siblings and increased percentage of male patients with FNMTC compared to those with sporadic NMTC. Many studies have apparently shown good evidence for putative susceptibility genes, but subsequent analysis has often contradicted these findings. Probably, the disparity in results may be explained by the variation in study designs as the differences in the inclusion criteria. Some studies analyzed FNMTC families with only two affected members whereas others enrolled FNMTC families with at least three first degree relatives to reduce the possibility of a random association of sporadic tumors. In addition, many studies were conducted only on single kindred or in small size families with a variety of additional benign common thyroid disorders. Hypothesized susceptibility genes are reported in Table 4 [32-36]. Among them, there is some evidence that HABP2 G534E variant (chromosome 10q25.3) is a susceptibility gene for FNMTC. In 2015, Gara et al. published in New England J of Medicine [32], the presence of a germline p.G534E variant in the $H A B P 2$ gene in seven affected members of a huge kindred with familial non-medullary thyroid cancer and in $4.7 \%$ of 423 patients with sporadic thyroid cancer. $H A B P 2$ gene encodes a member of the peptidase $\mathrm{S} 1$ family of serine proteases which bounds hyaluronic acid playing a role in the coagulation and fibrinolysis systems. In the study of Gara et al., the variant was associated with increased HABP2 protein expression in tumor samples from affected family members, as compared with normal adjacent thyroid tissue and sporadic cancers. Functional studies showed that HABP2 had a tumor-suppressive effect, whereas the G534E variant results in loss of function. These observations lead the authors to conclude that the $H A B P 2$ p.G534E is a susceptibility gene for familial non-medullary thyroid cancer. The impact of these results prompted several authors to search for the HABP2 p.G534E variant in other kindreds. All these studies failed in detecting the p.G534E mutation in FNMTC suggesting that Gara et al. identified a private variation $[37,38]$. However, recently, a study by Colombo

Table 4 Susceptibility genes associated with familial non-medullary thyroid cancer (FNMTC)

\begin{tabular}{lll}
\hline References & Location & Gene \\
\hline$[32]$ & $10 \mathrm{q} 25.3$ & HABP2 \\
{$[33]$} & $12 \mathrm{q} 14$ & SRGAP1 \\
{$[34]$} & $9 \mathrm{pq} 22.33$ & FOXE1 \\
{$[35]$} & $14 \mathrm{q} 13$ & TITF-1/NKX2.1 \\
{$[36]$} & $15 \mathrm{q} 23$ & MAP2K5 \\
\hline
\end{tabular}

et al., revealed that the HABP2 p.G534E does not segregate with cancer but its mRNA had a very variable expression in tissues from FNMTC, sporadic papillary thyroid cancers (PTCs) or contralateral normal tissues opening again a question on $H A B P 2$ role in thyroid cancer [39]. Some studies have demonstrated that FNMTC patients have shorter germline and somatic telomere length suggesting the role of telomere shortening in the development of FNMTC [40-42]. A recent paper reinforced these data, showing that the percentage of patients with short RTL was greater among those with FPTC than among those with sporadic PTCs and showed that leukocyte telomere length was significantly associated with PTC risk. These findings supported the hypothesis that telomere length is significantly correlated with susceptibility to PTC [43]. However, another study did not shown any differences in telomere length and telomerase activity between familial and sporadic PTC cases [44]. The presence of shorter telomeres has been clinically associated with the presence of genetic anticipation with the second generation acquiring the disease at an earlier age and having more advanced disease at presentation, reinforcing the hypothesis that FNMTC is a true familial disease rather than the fortuitous association of the same disease in a family [18]. In conclusion, at the moment, a known driving gene for familial non-medullary thyroid cancer has not been identified. Many published pedigrees suggest an autosomal dominant mode of inheritance with reduced penetrance, but polygenic inheritance cannot be excluded. For this reason, it would be appropriate to create, in agreement with all the medical centers that deal with this type of research, an international consortium for the recruitment of families with recurrence of NMTC and to allow the creation of a wide database and tissue bank where to collect a large quantity of material. This possibility would allow to carry out large-scale studies, to standardize FNMTC patient selection criteria and the application of the new molecular research techniques in an attempt to discover the pathogenetic mechanism(s) that leads to FNMTC development.

\section{Controversies in management of FNMTC}

Families with FNMTC present a unique challenge in clinical practice, as question regarding the need for screening and the need for aggressive initial therapy remain controversial $[45,46]$. While the debate regarding these topics has been going on for years, the context of these questions has changed with our current understanding of sporadic disease, including recognition of the large reservoir of DTC in the general population, the risks associated with over-diagnosis and over-treatment, and the trend for less aggressive therapy for early-stage DTC. We, therefore, address the topics of screening and extent of therapy in light of current literature. 


\section{Screening}

While screening for non-familial DTC is considered unnecessary or even potentially harmful [47], some authors have proposed annual screening in families with FNMTC. Advocates of screening point to higher rates of DTC in firstdegree kindreds, and to several studies which demonstrated more advanced disease at presentation leading to worse outcome in these families, though data on these topics are conflicting.

A recent prospective study with yearly screening of atrisk individuals from families with FNMTC at the National Institutes of Health (NIH) by Klubo-Gwiezdzinska et al. [48] found thyroid cancer by ultrasound screening in $4.6 \%$ individuals from families with two members affected (similar to the estimated prevalence in the general population of $4.5 \%$ ) $[16,49]$ and in $22.7 \%$ of members from families with three or more patients affected. Similar results were reported in a prospective study by Rios et al. [50], which screened families with mostly two affected members, and found 5.5\% incidence of thyroid cancer. Using a mathematical analysis of the SEER (Surveillance Epidemiology and End Results) database, Charkes [15] concluded that up to $62 \%$ of 2-hit families may be sporadic occurrences, while the chance of sporadic DTC in families of three or more affected members is less than $6 \%$. These data highlight the need to differentiate between screening in the relatively common 2-hit families with relatively low DTC detection rate, from those with three or more affected members where high detection rate is expected from first degree screening.

Screening would also be recommended if early detection and treatment would lead to decreased mortality or improved quality of life in affected families. Unfortunately, no interventional screening programs have reported these outcomes. Currently, proponents of screening point to some (but not all) studies reporting of disease appearance at an earlier age [16, 45, 51-55], and studies reporting more advanced disease at presentation leading to worse outcomes, especially in patients with three or more affected members $[45,53,54$, 56-60]. However, published studies are conflicting, with one meta-analysis and several studies reporting clinical course and outcome similar to sporadic disease [61-64].

Current guidelines, including the adult and pediatric ATA guidelines [65, 66], do not recommend for or against U/S screening in non-syndromic FNMTC, apart from routine physical examination. However, in light of the recent NIH study discussed above, it seems reasonable to recommend screening with yearly U/S in kindred with three or more affected family members, starting from the age of 20 or 10 years before the earliest age of the diagnosis in the family. For families with only two affected family members, there are insufficient data to recommend yearly U/S screening, given the likelihood of sporadic disease aggregated in one family, and the risk of over-diagnosis and over-treatment. In cases of syndromic familial DTC, published recommendation are available for screening in PTEN hamartoma tumor syndrome and APC-associated polyposis [67-69].

\section{Extent of therapy}

To determine whether patients with FNMTC require more aggressive therapy, it is important to differentiate between studies evaluating disease presentation (comparing consecutive patients with FNMTC with consecutive patients with sporadic disease, often with different baseline characteristics) $[16,18,51-54,56,57,60,64,70-73]$, from studies evaluating outcome in groups which are matched for baseline characteristics $[61,63,74]$.

While a more aggressive disease at presentation (larger tumors, more extra-thyroidal extension or more lymph nodes involvement) would serve as an argument for screening, it does not imply that standard risk-adjusted therapy would not be effective for these patients. For example, if on average patients with FNMTC have more lymph node involvement at presentation (and therefore more recurrences), it does not imply that a patient with a familial $1.1-\mathrm{cm}$ intra-thyroidal PTC would benefit from higher activities of radioiodine therapy as compared to a similar patient with sporadic disease. Hence, the extent of therapy should be guided by controlled studies with comparable groups, with a focus on response to therapy and disease outcome.

In a multicenter case-control study by Alsanea et al. published in 2000, 48 American and Japanese patients with FNMTC were matched with 114 patients with sporadic disease for age, gender, stage at presentation, and history of radiation exposure [74]. Patients with FNMTC had a significantly shorter disease-free survival, with the worst outcome in patients with distant metastases and with more than two affected family members. In contrast, Cao et al. [61] published a large study in 2016 of 372 Chinese patients with FNMTC matched with 372 sporadic cases for gender, age, tumor/node/metastasis (TNM) staging, and approximate duration of follow-up. There was no significant difference in recurrences ( $7.8 \%$ vs. $5.4 \%$, respectively) or disease-related mortality (one patient in each group), with a significant difference only in the $<1 \mathrm{~cm}$ subgroup recurrence rate (7.3 vs. $1.3 \%, p=0.002)$. Similar outcomes were also demonstrated in a small Canadian matched case-control study from 2004 [63] where 24 FNMTC cases were matched with 24 sporadic cases for age, gender, stage, and tumor size. There was no difference in surgical management or recurrence between the two groups.

Multiple other studies compared consecutive patients with FNMTC with sporadic cases (often with different baseline characteristics), with mixed results in terms of disease outcome. Most studies reported of more aggressive 
disease at presentation leading to worse outcome in the FNMTC group [18, 52-54, 70]. However, several studies reported of more aggressive disease at presentation with similar outcome at the end of follow-up [60, 64, 71, 73, 75], or of similar baseline characteristics with similar outcome [18,72] or worse outcome [57]. These differences may result from the retrospective design of the studies, small sample size, inclusion of families with both two and three affected kindreds, and genetic variability across populations.

Overall, patients with FNMTC tend to have more advanced disease at presentation and, therefore, tend to receive more aggressive initial therapy. However, there are no data to suggest their response to initial therapy (surgery or radioiodine) is different compared to sporadic cases, and therefore, there is insufficient evidence to suggest more aggressive surgery or higher activities of radioiodine, above what would be usually recommended for a specific disease stage. It is worth noting, however, that current trends of less aggressive therapy for sporadic DTC were not evaluated in families with FNMTC, and treatment with total thyroidectomy and radioiodine is reasonable, especially in patients with three or more affected members.

\section{Conclusions}

Familial non-medullary thyroid carcinoma represents an interesting challenge for clinician because many aspects of this disease still need to be clarified, from its definition to genetic and clinical aspects. There are conflicting data on aggressiveness of FNMTC compared to sporadic form and the latest ATA guidelines do not recommend a different therapeutic approach for FNMTC patients. However, the possibility of a family history as a risk factor for DTC underlines the importance of an accurate anamnesis. Some clinical parameters such as the diagnosis of FNMTC at a relative young age associated with the presence of tumor multicentricity and/or bilaterality are elements that must draw attention to a possible form of familial cancer. The availability of a specific genetic marker in the future will allow a diagnosis of certainty and individually tailor the optimal screening and treatment.

Acknowledgements No grants or fellowships have supported the writing of the paper.

Funding Open access funding provided by Università degli Studi di Siena within the CRUI-CARE Agreement. No funding was received for this research.

\section{Compliance with ethical standards}

Conflict of interest The authors have no conflicts of interest to report.

Ethical approval This article does not contain any studies with human participants or animals performed by any of the authors.

Informed consent For this type of study, formal consent is not required.

Open Access This article is licensed under a Creative Commons Attribution 4.0 International License, which permits use, sharing, adaptation, distribution and reproduction in any medium or format, as long as you give appropriate credit to the original author(s) and the source, provide a link to the Creative Commons licence, and indicate if changes were made. The images or other third party material in this article are included in the article's Creative Commons licence, unless indicated otherwise in a credit line to the material. If material is not included in the article's Creative Commons licence and your intended use is not permitted by statutory regulation or exceeds the permitted use, you will need to obtain permission directly from the copyright holder. To view a copy of this licence, visit http://creativecommons.org/licenses/by/4.0/.

\section{References}

1. Mai PL, Garceau AO, Graubard BI, Dunn M, McNeel TS, Gonsalves L, Gail MH, Greene MH, Willis GB, Wideroff L (2011) Confirmation of family cancer history reported in a population-based survey. J Natl Cancer Inst 103:788-797. https://doi. org/10.1093/jnci/djr114

2. Syngal S, Brand RE, Church JM, Giardiello FM, Hampel HL, Burt RW (2015) ACG clinical guideline: genetic testing and management of hereditary gastrointestinal cancer syndromes. Am J Gastroenterol 110:223. https://doi.org/10.1038/ajg.2014.435

3. Byun J, Schwartz AG, Lusk C et al (2018) Genome-wide association study of familial lung cancer. Carcinogenesis 39:1135-1140

4. Kluijt I, Sijmons RH, Hoogerbrugge N et al (2012) Familial gastric cancer: guidelines for diagnosis, treatment and periodic surveillance. Fam Cancer 11:363-369

5. Arpino G, Pensabene M, Condello C, Ruocco R, Cerillo I, Lauria R, ForestieriV Giuliano M, De Angelis C, Montella M, Crispo A, De Placido S (2016) Tumor characteristics and prognosis in familial breast cancer. BMC Cancer 16:924

6. Gandini S, Sera F, Cattaruzza MS et al (2005) Meta-analysis of risk factors for cutaneous melanoma, III: family history, actinic damage and phenotypic factors. Eur J Cancer 41:2040-2059

7. Ostrander EA, Markianos K, Stanford JL (2004) Finding prostate cancer susceptibility genes. Annu Rev Genomics Hum Genet 5:151-175

8. Frank C, Fallah M, Sundquist J, Hemminki A, Hemminki K (2015) Population landscape of familial cancer. Sci Rep. 5:12891. https://doi.org/10.1038/srep12891

9. Matthews AG, Finkelstein DM, Betensky RA (2008) Analysis of familial aggregation studies with complex ascertainment schemes. Stat Med 27:5076-5092. https://doi.org/10.1002/sim.3327

10. Murff HJ, Spigel DR, Syngal S (2004) Does this patient have a family history of cancer? An evidence-based analysis of the accuracy of family cancer history. JAMA 292:1480-1489

11. Robinson DW, Orr TG (1955) Carcinoma of the thyroid and other diseases of the thyroid in identical twins. AMA Arch Surg 70:923-928 
12. Malchoff CD, Malchoff DM (2006) Familial nonmedullary thyroid carcinoma. Cancer Control 13:106-110

13. Frich L, Glattre E, Akslen LA (2001) Familial occurrence of nonmedullary thyroid cancer: a population-based study of 5673 firstdegree relatives of thyroid cancer patients from Norway. Cancer Epidemiol Biomarkers Prev 10:113-117

14. Goldgar DE, Easton DF, Cannon-Albright LA, Skolnick MH (1994) Systematic population-based assessment of cancer risk in first-degree relatives of cancer probands. J Natl Cancer Inst $86: 1600-1608$

15. Charkes ND (2006) On the prevalence of familial nonmedullary thyroid cancer in multiply affected kindreds. Thyroid 16:181-186

16. Moses W, Weng J, Kebebew E (2011) Prevalence, clinicopathologic features, and somatic genetic mutation profile familial versus sporadic nonmedullary thyroid cancer. Thyroid 21:367-371

17. Brandt A, Bermejo JL, Sundquist J, Hemminki K (2008) Age of onset in familial cancer. Ann Oncol 19:2084-2088

18. Capezzone M, Marchisotta S, Cantara S, Busonero G, Brilli L, Pazaitou-Panayiotou K, Carli AF, Caruso G, Toti P, Capitani S, Pammolli A, Pacini F (2008) Familial non-medullary thyroid carcinoma displays the features of clinical anticipation suggestive of a distinct biological entity. Endocr Relat Cancer 15:1075-1078

19. Bignell GR, Canzian F, Shayeghi M et al (1997) Familial nontoxic multinodular thyroid goiter locus maps to chromosome $14 \mathrm{q}$ but does not account for familial nonmedullary thyroid cancer. Am J Hum Genet 61(5):1123-1130

20. Bakhsh A, Kirov G, Gregory JW, Williams ED, Ludgate M (2006) A new form of familial multi-nodular goitre with progression to differentiated thyroid cancer. Endocr Relat Cancer 13(2):475-483

21. Peiling Yang S, Ngeow J (2016) Familial non-medullary thyroid cancer: unraveling the genetic maze. Endocr Relat Cancer 23:R577-R595

22. Cetta F, Montalto G, Gori M, Curia MC, Cama A, Olschwang S (2000) Germline mutations of the APC gene in patients with familial adenomatous polyposis-associated thyroid carcinoma: results from a European cooperative study. J Clin Endocrinol Metab 85:286-292

23. Liaw D, Marsh DJ, Li J et al (1997) Germline mutations of the PTEN gene in Cowden disease, an inherited breast and thyroid cancer syndrome. Nat Genet 16:64-67

24. Stratakis CA, Courcoutsakis NA, Abati A et al (1997) Thyroid gland abnormalities in patients with the syndrome of spotty skin pigmentation, myxomas, endocrine overactivity, and schwannomas (Carney complex). J Clin Endocrinol Metab 82:2037-2043

25. Yu CE, Oshima J, Fu YH et al (1996) Positional cloning of the Werner's syndrome gene. Science 272:258-262

26. Rio Frio T, Bahubeshi A, Kanellopoulou C et al (2011) DICER1 mutations in familial multinodular goiter with and without ovarian Sertoli-Leydig cell tumors. JAMA 305:68-77

27. Canzian F, Amati P, Harach HR, Kraimps JL, Lesueur F, Barbier J, Levillain P, Romeo G, Bonneau D (1998) A gene predisposing to familial thyroid tumors with cell oxyphilia maps to chromosome 19p13.2. Am J Hum Genet 63:1743-1748

28. Bevan S, Pal T, Greenberg CR, Green H, Wixey J, Bignell G, Narod SA, Foulkes WD, Stratton MR, Houlston RS (2001) A comprehensive analysis of MNG1, TCO1, fPTC, PTEN, TSHR, and TRKA in familial nonmedullary thyroid cancer: confirmation of linkage to TCO1. J Clin Endocrinol Metab 86:3701-3704

29. Malchoff CD, Sarfarazi M, Tendler B, Forouhar F, Whalen G, Joshu V, Arnold A, Malchoff DM (2000) Papillary thyroid carcinoma associated with papillary renal neoplasia: genetic linkage analysis of a distict heritable tumor sindrome. J Clin Endocrinol Metab 85:1758-1764

30. McKay JD, Thompson D, Lesueur F, Stankov K, Pastore A, Watfah C, Strolz S, Riccabona G, Moncayo R, Romeo G, Goldgar DE (2004) Evidence for interaction between the TCO and NMTC1 loci in familial non-medullary thyroid cancer. J Med Genet 41:407-412

31. McKay JD, Lesueur F, Jonard L et al (2001) Localization of a susceptibility gene for familial nonmedullary thyroid carcinoma to chromosome 2q21. Am J Hum Genet 69:440-446

32. Gara SK, Jia L, Merino MJ, Agarwal SK, Zhang L, Cam M, Patel D, Kebebew E (2015) Germline HABP2 Mutation Causing Familial Nonmedullary Thyroid Cancer. N Engl J Med 373:448-455

33. He H, Bronisz A, Liyanarachchi S et al (2013) SRGAP1 is a candidate gene for papillary thyroid carcinoma susceptibility. J Clin Endocrinol Metab 98(5):E973-E980

34. Pereira JS, da Silva JG, Tomaz RA, Pinto AE, Bugalho MJ, Leite V, Cavaco BM (2015) Identification of a novel germline FOXE1 variant in patients with familial non-medullary thyroid carcinoma (FNMTC). Endocrine 49:204-214

35. Ngan ES, Lang BH, Liu T, Shum CK, So MT, Lau DK, Leon TY, Cherny SS, Tsai SY, Lo CY, Khoo US, Tam PK, GarciaBarceló MM (2009) A germline mutation (A339V) in thyroid transcription factor-1 (TITF-1/NKX2.1) in patients with multinodular goiter and papillary thyroid carcinoma. J Natl Cancer Inst 101:162-175

36. Ye F, Gao H, Xiao L et al (2019) Whole exome and target sequencing identifies MAP2K5 as novel susceptibility gene for familial non-medullary thyroid carcinoma. Int J Cancer 144:1321-1330

37. Weeks AL, Wilson SG, Ward L, Goldblatt J, Hui J, Walsh JP (2016) HABP2 germline variants are uncommon in familial nonmedullary thyroid cancer. BMC Med Genet 17:60. https://doi. org/10.1186/s12881-016-0323-1

38. Cantara S, Marzocchi C, Castagna MG, Pacini F (2017) HABP2 G534E variation in familial non-medullary thyroid cancer: an Italian series. J Endocrinol Invest 40:557-560

39. Colombo C, Muzza M, Proverbio MC, Ercoli G, Perrino M, Cirello V, Vicentini L, Ferrero S, Fugazzola L (2017) Segregation and expression analyses of hyaluronan-binding protein 2 (HABP2): insights from a large series of familial non-medullary thyroid cancers and literature review. Clin Endocrinol 86:837-844

40. Capezzone M, Cantara S, Marchisotta S, Filetti S, De Santi MM, Rossi B, Ronga G, Durante C, Pacini F (2008) Short telomeres, telomerase reverse transcriptase gene amplification, and increased telomerase activity in the blood of familial papillary thyroid cancer patients. J Clin Endocrinol Metab 93:3950-3957

41. Capezzone M, Cantara S, Marchisotta S, Busonero G, Formichi C, Benigni M, Capuano S, Toti P, Pazaitou-Panayiotou K, Caruso G, Carli AF, Palummo N, Pacini F (2011) Telomere length in neoplastic and nonneoplastic tissues of patients with familial and sporadic papillary thyroid cancer. J Clin Endocrinol Metab 96:E1852-E1856

42. He M, Bian B, Gesuwan K et al (2013) Telomere length is shorter in affected members of families with familial nonmedullary thyroid cancer. Thyroid 23:301-307

43. Li J, An C, Zheng H et al (2019) Leukocyte Telomere Length and Risk of Papillary Thyroid Carcinoma. J Clin Endocrinol Metab 104:2712-2718

44. Jendrzejewski J, Tomsic J, Lozanski G, Labanowska J, He H, Liyanarachchi S, Nagy R, Ringel MD, Kloos RT, Heerema NA, de la Chapelle A (2011) Telomere length and telomerase reverse transcriptase gene copy number in patients with papillary thyroid carcinoma. J Clin Endocrinol Metab 96:E1876-E1880

45. Mazeh H, Sippel RS (2013) Familial nonmedullary thyroid carcinoma. Thyroid Off J Am Thyroid Assoc 23:1049-1056

46. Nixon IJ, Suárez C, Sim R, Sanabria A, Angelos P, Rinaldo A, Rodrigo JP, Kowalski LP, Hartl DM, Hinni ML, Shah JP, Ferlito A (2016) The impact of family history on non-medullary thyroid cancer. Eur J Surg Oncol J Eur Soc Surg Oncol Br Assoc Surg Oncol 42:1455-1463 
47. US Preventive Services Task Force, Bibbins-Domingo K, Grossman DC, Curry SJ, Barry MJ, Davidson KW, Doubeni CA, Epling JW, Kemper AR, Krist AH, Kurth AE, Landefeld CS, Mangione CM, Phipps MG, Silverstein M, Simon MA, Siu AL, Tseng CW (2017) Screening for thyroid cancer: US preventive services task force recommendation statement. JAMA 317:1882-1887

48. Klubo-Gwiezdzinska J, Yang L, Merkel R, Patel D, Nilubol N, Merino MJ, Skarulis M, Sadowski SM, Kebebew E (2017) Results of screening in familial non-medullary thyroid cancer. Thyroid Off J Am Thyroid Assoc 27:1017-1024

49. Furuya-Kanamori L, Bell KJL, Clark J, Glasziou P, Doi SAR (2016) Prevalence of differentiated thyroid cancer in autopsy studies over six decades: a meta-analysis. J Clin Oncol Off J Am Soc Clin Oncol 34:3672-3679

50. Ríos A, Rodríguez JM, Navas D, Cepero A, Torregrosa NM, Balsalobre MD, Parrilla P (2016) Family screening in familial papillary carcinoma: the early detection of thyroid disease. Ann Surg Oncol 23:2564-2570

51. Ito Y, Kakudo K, Hirokawa M, Fukushima M, Yabuta T, Tomoda C, Inoue H, Kihara M, Higashiyama T, Uruno T, Takamura Y, Miya A, Kobayashi K, Matsuzuka F, Miyauchi A (2009) Biological behavior and prognosis of familial papillary thyroid carcinoma. Surgery 145:100-105

52. Mazeh H, Benavidez J, Poehls JL, Youngwirth L, Chen H, Sippel RS (2012) In patients with thyroid cancer of follicular cell origin, a family history of nonmedullary thyroid cancer in one first-degree relative is associated with more aggressive disease. Thyroid Off J Am Thyroid Assoc 22:3-8

53. Park YJ, Ahn HY, Choi HS, Kim KW, Park DJ, Cho BY (2012) The long-term outcomes of the second generation of familial nonmedullary thyroid carcinoma are more aggressive than sporadic cases. Thyroid Off J Am Thyroid Assoc 22:356-362

54. Tavarelli M, Russo M, Terranova R, Scollo C, Spadaro A, Sapuppo G, Malandrino P, Masucci R, Squatrito S, Pellegriti G (2015) Familial non-medullary thyroid cancer represents an independent risk factor for increased cancer aggressiveness: a retrospective analysis of 74 families. Front Endocrinol 6:117

55. Wang X, Cheng W, Li SuA, Wei T, Liu F, Zhu J (2015) Endocrine tumours: familial nonmedullary thyroid carcinoma is a more aggressive disease: a systematic review and meta-analysis. Eur J Endocrinol 172:R253-R262

56. Fan YF, Zhang B, Yang X, Shang ZH, Liu HF, Xie Y, Liu YW, Gao WS, Wu Q, Li XY (2015) Clinicopathologic features of familial nonmedullary thyroid carcinoma. Chin Med J (Engl) 128:1037-1041

57. Lee Y-M, Yoon JH, Yi O, Sung T-Y, Chung K-W, Kim WB, Hong SJ (2014) Familial history of non-medullary thyroid cancer is an independent prognostic factor for tumor recurrence in younger patients with conventional papillary thyroid carcinoma. J Surg Oncol 109:168-173

58. Lei S, Wang D, Ge J, Liu H, Zhao D, Li G, Ding Z (2015) Singlecenter study of familial papillary thyroid cancer in China: surgical considerations. World J Surg Oncol 13:115

59. McDonald TJ, Driedger AA, Garcia BM, Van Uum SHM, Rachinsky I, Chevendra V, Breadner D, Feinn R, Walsh SJ, Malchoff CD (2011) Familial papillary thyroid carcinoma: a retrospective analysis. J Oncol 2011:948786

60. Uchino S, Noguchi S, Kawamoto H, Hi Yamashita, Watanabe S, Yamashita H, Shuto S (2002) Familial nonmedullary thyroid carcinoma characterized by multifocality and a high recurrence rate in a large study population. World J Surg 26:897-902

61. Cao J, Chen C, Chen C, Wang QL, Ge MH (2016) Clinicopathological features and prognosis of familial papillary thyroid carcinoma-a large-scale, matched, case-control study. Clin Endocrinol (Oxf) 84:598-606

62. Loh C (1997) Familial nonmedullary thyroid carcinoma: a metareview of case series. Thyroid Off J Am Thyroid Assoc 7:107-113
63. Maxwell EL, Hall F, Freeman JL (2004) Familial non-medullary thyroid cancer: a matched-case control study. The Laryngoscope 114:2182-2186

64. Pitoia F, Cross G, Salva ME, Abelleira E, Niepomniszcze H (2011) Patients with familial non-medullary thyroid cancer have an outcome similar to that of patients with sporadic papillary thyroid tumors. Arq Bras Endocrinol Metabol 55:219-223

65. Haugen BR, Alexander EK, Bible KC et al (2016) American Thyroid Association Management Guidelines for Adult Patients with Thyroid Nodules and Differentiated thyroid cancer: the American Thyroid Association Guidelines Task Force on thyroid nodules and differentiated thyroid cancer. Thyroid 26:1-133

66. Francis GL, Waguespack SG, Bauer AJ, Angelos P, Benvenga S, Cerutti JM, Dinauer CA, Hamilton J, Hay ID, Luster M, Parisi M, Rachmiel M, Thompson GB, Yamashita S, American Thyroid Association Guidelines Task Force (2015) Management guidelines for children with thyroid nodules and differentiated thyroid cancer. Thyroid Off J Am Thyroid Assoc 25:716-759

67. Ngeow J, Mester J, Rybicki LA, Ni Y, Milas M, Eng C (2011) Incidence and clinical characteristics of thyroid cancer in prospective series of individuals with Cowden and Cowden-like syndrome characterized by germline PTEN, SDH, or KLLN alterations. J Clin Endocrinol Metab 96:E2063-E2071

68. Smith JR, Marqusee E, Webb S, Nose V, Fishman SJ, Shamberger RC, Frates MC, Huang SA (2011) Thyroid nodules and cancer in children with PTEN hamartoma tumor syndrome. J Clin Endocrinol Metab 96:34-37

69. Steinhagen E, Guillem JG, Chang G, Salo-Mullen EE, Shia J, Fish S, Stadler ZK, Markowitz AJ (2012) The prevalence of thyroid cancer and benign thyroid disease in patients with familial adenomatous polyposis may be higher than previously recognized. Clin Colorectal Cancer 11:304-308

70. Hillenbrand A, Varhaug JE, Brauckhoff M, Pandev R, Haufe S, Dotzenrath C, Köberle R, Hoffmann R, Klein G, Kadmon M, Negele T, Hagieva T, Henne-Bruns D, Luster M, Weber T (2010) Familial nonmedullary thyroid carcinoma-clinical relevance and prognosis. A European multicenter study. ESES Vienna presentation. Langenbecks Arch Surg 395:851-858

71. Jiwang L, Zhendong L, Shuchun L, Bo H, Yanguo L (2015) Clinicopathologic characteristics of familial versus sporadic papillary thyroid carcinoma. Acta Otorhinolaryngol Ital 35:234-242

72. Robenshtok E, Tzvetov G, Grozinsky-Glasberg S, Shraga-Slutzky I, Weinstein R, Lazar L, Serov S, Singer J, Hirsch D, Shimon I, Benbassat C (2011) Clinical characteristics and outcome of familial nonmedullary thyroid cancer: a retrospective controlled study. Thyroid Off J Am Thyroid Assoc 21:43-48

73. Zhang Q, Yang S, MengX Chen G, Pang R (2016) Clinical analysis of familial nonmedullary thyroid carcinoma. World J Surg 40:570-573

74. Alsanea O, Wada N, Ain K, Wong M, Taylor K, Ituarte PH, Treseler PA, Weier HU, Freimer N, Siperstein AE, Duh QY, Takami $\mathrm{H}$, Clark OH (2000) Is familial non-medullary thyroid carcinoma more aggressive than sporadic thyroid cancer? A multicenter series. Surgery 128:1043-1050 (Discussion 1050-1051)

75. Capezzone M, Fralassi N, Secchi C, Cantara S, Brilli L, Pilli T, Maino F, Forleo R, Pacini F, Cevenini G, Cartocci A, Castagna MG (2020) long-term clinical outcome in familial and sporadic papillary thyroid carcinoma. Eur Thyroid J. https://doi. org/10.1159/000506955

Publisher's Note Springer Nature remains neutral with regard to jurisdictional claims in published maps and institutional affiliations. 